\title{
Correspondence
}

\section{Mental Health Commissions for England and Wales}

\section{Dear Sir}

I have been following the work of the Special Committee for the Review of the Mental Health Act with nostalgic interest. My reason for writing is that, despite the efforts of the College, the DHSS remains for the moment unmoved. The Lancet note is pessimistic though the time is clearly ripe for change. I suspect that political pressures are the main obstructive factors - as they were, say, in the heyday of the previous Tory administrations under Enoch Powell. This present situation concerns me so much that, though retired from my Chair, and more recently from the Mental Welfare Commissions (MWC) for Scotland, I try to keep in touch.

It is the experience of the MWC that may be of some value to the College, since I was not only one of the two or three on the original Dunlop Committee (advising on the Scottish Bill which went against the English Bill on the issues of Board of Control abolition and the explicit introduction of the category 'psychopath') but also a founder member of the MWC under the chairmanship of the late Sir Hugh Rose until 1978, when we had the present outstanding chairman, Lord Macdonald.

The question of a similar Commission (or Commissions) in England and Wales has come up from the very early years after we were set up in 1962. Several of us were invited to be present at Tribunals (though I was kicked out when the legal chairman decided my presence would somehow be prejudicial when they went into secret session to decide the fate of a pathetic subnormal who was 'released' after what was almost a trial of the consultant in charge). My own and my fellow Commissioners' views of these Tribunals would have made inflammatory reading had they been published.

Our own conclusion was that the Commission worked well in Scotland because the Board of Control had also been much more successful in keeping in personal touch with both patients and staff. In England and Wales there was an inevitable remoteness that obliged Commissioners (who were, of course, Health Service or Government employees after 1946- and became mere inspectors of fabric and food) to restrict their activities to those of bureaucrats. Hence the universal view of the Royal Commission that inspectorial functions should become the province of the Health Minister directly and any independent functions scrapped.

It was the scrapping of the other functions that proved a disastrous error, for in them were contained protective functions in respect of thousands of individual patients left totally exposed to bureaucratic neglect-save where they could summon up enough resource on their own behalf and appeal to a nameless and remote Tribunal.
The appalling oversight was that the psychiatric patients are not in every respect to be treated as all other patients, plausible though this view is in so many respects. The crucial difference is that psychiatric patients, by definition, require special care, treatment and protection - from themselves and others. Thus some independent body, identified solely with these special needs, requires to be set up, and this is what the MWC has become. I may say that Sir Hugh Rose was the main force in pushing the letter of the Act to the limit in insisting on returns from hospitals, demanding powers to visit regularly, to make reports, and keep hospital staff and guardians toeing the line. He actually took the powers against strong but ineffectual protests from Department Chiefs who kept saying 'But you can't do that, it's not stated in the Act'. To which he replied 'Can't I, just watch ...'

It seems to me that your report has perhaps not made enough of this vital principle: that leaving things as they are, leaving the initiative for appeals, complaints, etc, to patients, their relatives and such pressure groups as MIND and Scientology (if they differ), and not taking the initiative in becoming paternalistic is crucial. It may be that some better word than paternalistic is required. But the concept is clear enough! Mental patients need looking after as individuals and all concerned in hospital should be assisted to make this pussible. It is remarkable how this concern for one single individual patient by the MWC has led to generalizations that have been of benefit to whole hospitals or to the Service as a whole. All suicides for example are reported to the MWC in detail. We learn that, say, lysol, or falling out of a window led to their death. We can then take up with staff and management modifications to routine or to buildings. Again, if we find that one ex-serviceman has no war pension we look into it and find that there was a national regulation excluding mental patients from pensions while in hospital. Several million pounds had to be returned by a chastened government department throughout the UK as a result of our pressures over some years.

In short, the MWC has been a troubleshooter from the start, hence no 'atrocity' inquiries (though we came close to several which were headed off in time). The complacency of the DHSS amazes me, since there have been so many atrocities and so many inquiries which themselves must have cost far in excess of modestly staffed Commissions. But finance is a poor argument, for, even if Commissions do cost more, surely the saving in human misery as demonstrated by all the inquiries justifies the preventive functions of a Commission being set up.

2 South Avenue,

W. MALCOLM MILLAR

Cults, Aberdeen AB2 ILP 